\title{
TITLE:
}

\section{Crack growth in Westerly granite during a cyclic loading test}

\section{$\operatorname{AUTHOR}(\mathrm{S})$ :}

Chen, Youqing; Watanabe, Kota; Kusuda, Hiromu; Kusaka, Eishi; Mabuchi, Mamoru

\section{CITATION:}

Chen, Youqing ... [et al]. Crack growth in Westerly granite during a cyclic loading test. Engineering Geology 2011, 117(3-4): 189-197

\section{ISSUE DATE:}

2011-02-02

URL:

http://hdl.handle.net/2433/139251

\section{RIGHT:}

(C) 2010 Elsevier B.V.; This is not the published version. Please cite only the published version.; この論文は出版社版でありません。引用の際に は出版社版をご確認ご利用ください。 
Crack growth in Westerly granite during a cyclic loading test

Youqing CHEN ${ }^{\mathrm{a}^{*}}$, Kota WATANABE ${ }^{\mathrm{a}}$, Hiromu KUSUDA ${ }^{\mathrm{a}}$, Eishi KUSAKA ${ }^{\mathrm{a}}$, Mamoru MABUCHI $^{\mathrm{a}}$

${ }^{\text {a }}$ Graduate School of Energy Science, Kyoto University, Yoshida-Honmachi, Sakyo-ku, Kyoto, 606-8501, Japan

*Corresponding author

E-mail: chen@energy.kyoto-u.ac.jp (Y.Chen).

\section{ABSTRACT}

To examine the fatigue process of granite, cylindrical Westerly granite specimens, $10 \mathrm{~mm}$ in diameter and $20 \mathrm{~mm}$ in length, were subjected to a cyclic loading test under uniaxial compression with a maximum of $140 \mathrm{MPa}$ at room temperature, and crack growth patterns within them were analyzed by microscopic observation and image analysis techniques. The fatigue process is divided into three characteristic stages; a primary stage in which the upper peak strain increases at a decelerating rate (stage I), a second stage with linearly slight increasing rate of strain following stage I (stage II), and the third and final stage in which the upper peak strain increases at an accelerating rate and culminates in specimen failure (stage III). A series of prefailure specimens, of which the stage in the fatigue process was decided by monitoring the strain behavior during the test, were retrieved. In addition, these specimens were compared with specimens stressed to close to the breaking strength by monotonic compression to examine the characteristic features of fatigue. The fluorescent method was applied to 
identify microcracks within the specimens. The advantage of this method is to provide quick and accurate identification of microcracks with an optical microscope. Microcracks are detected based on a marked difference in brightness under ultraviolet light irradiation because they are fully filled with acrylic resin mixed with a fluorescent substance in advance. Thin sections, including the axis of the specimen, $10 \times 20 \mathrm{~mm}$, were prepared for detailed observation after the pretreatment of the method.

The results were as follows. At the initial degradation stage, distinguishing crack growth was identified in quartz grains. It is estimated that the slowdown of the strain growth rate at this stage was caused by the decrease in crack growth, that is, the portions with cracking potentiality were damaged at the first or early loading, and no further damage occurred immediately following the first damage. At the second stage, no significant crack growth in quartz grains was identified. On the other hand, in feldspar grains, development of cracks in a preferential direction, parallel to the loading direction, was observed. However, they did not grow into intergranular cracks by cutting across the grain boundaries during this stage. Consequently, it was found that a gradual progress of microcracks within feldspar grains was dominant during the second stage, and this is because the strain growth rate was in a steady and long state. At the final accelerated stage, many intergranular cracks running parallel to the loading direction were identified. It is obvious that these long cracks were formed mainly by the linking and growth of the intragranular cracks in feldspars, which were generated during the former stages. Their formation takes the fatigue process from the second stage to the final stage with a sharp increase in strain, and their further development seemed to lead the whole specimen to ultimate fatigue failure.

Keywords: Microcrack; Granite; Fatigue process; Uniaxial cyclic loading; Image analysis 


\section{Introduction}

In many cases, the structures constructed in underground spaces, e.g., traffic tunnels, mining galleries, and spaces for hydroelectric power plant pumps, are used over a prolonged period. Therefore, for the stability evaluation of many rock structures, it is important to reveal the deterioration characteristics of rocks under repeated stress alternation over the long term. In recent years, several new proposals for the usage of underground spaces have drawn increasing interest: compressed air energy storage systems, superconducting magnetic energy storage systems, underground nuclear-waste repositories, and so on. For example, the base rock surrounding the compressed air energy storage system has to bear cyclic stress changes in the first planning stage.

It is well-known that many materials deteriorate due to repeated stress changes over a prolonged period and then finally reach failure even if the change is below their static breaking strength. This phenomenon is generally known as 'fatigue'. Fatigue occurs in many kinds of materials (Suresh, 1998), and rock is no exception (Martin and Chandler, 1994; Eberhardt et al., 1999; Lau and Chandler, 2004; Heap et al., 2009). Many studies on the fatigue characteristics of rocks have been carried out since the 1960 's. Most of them stressed rock specimens cyclically using a loading machine. These primary studies reported that the fatigue life, i.e., the time or cycles taken to fail due to fatigue, was significantly influenced by the magnitude of the applied maximum stress (e.g., Burdine, 1963; Hardy and Chugh, 1970). Attempts to estimate the fatigue life were also conducted by many researchers (e.g., Suzuki et al., 1970; Costin and Holcomb, 1981). In many geological engineering problems, granite is one of the most important materials to investigate. The fatigue characteristics of granite have also been studied (e.g., Scholz and Koczynski, 1979; Kodama et al., 1992; Heap and Faulkner, 2008). To examine crack development during granite fatigue tests, samples were monitored by the acoustic emission method, and it was revealed that crack development 
increased with increasing stress cycles (Haimson, 1978). In recent years, Åkesson et al. (2004) reported a characteristic microcrack growth pattern in every constituent mineral by microscopic observation of failure granite specimens after cyclic loading, and Faulkner et al. (2006) discussed the increase of microfracture density with increasing damage by stepwise cyclic loading. However, the detail damaging process in granite fatigue, i.e., what kind of damage or cracking occurring in the phases from the onset of degradation until the final collapse and the relationship between the damage and the subsequent ones, has not been clarified. It is clear that in granite the initiation and elongation of microcracks play an essential role in the failure process. It is therefore necessary to examine the growth of cracks during the fatigue process.

Therefore, in this study, to examine the fatigue process in granite, cylindrical Westerly granite specimens were subjected to the cyclic loading test under uniaxial conditions at room temperature with a maximum applied stress of $140 \mathrm{MPa}$, and the patterns of microcracks at three characteristic stages during the test were observed microscopically, applying the fluorescent approach proposed by Nishiyama and Kusuda (1994). As a further examination, microcrack growth patterns were investigated by the digital image analysis technique. In addition, a comparison of crack development between cyclic loading and monotonic compression was made.

\section{Experimental}

\subsection{Sample}

Westerly granite, a fine-grained two mica granite from Rhode Island, USA, was chosen for the examination. Many investigations have been performed using this rock, and its fundamental characteristics have been detailed by many researchers (e.g., Scholz, 1968; Friedman et al., 1970; Tapponnier and Brace, 1976; Chen and Wang, 1980). It is reported that Westerly granite contains three splitting planes mostly perpendicular to 
each other. The test pieces in this study were prepared from one about $50 \mathrm{~cm}$ cube rock block with oriented marking and cored in the laboratory.

The modal composition of the tested samples was about $70 \%$ feldspars (potassium and plagioclase feldspar), 25\% quartz, and 5\% micas (biotite and muscovite) and accessories. The mean grain size was about $0.7 \mathrm{~mm}$. The connected porosity (measured by a water-evaporation method) of the specimens was around $1 \%$.

\subsection{Test conditions}

Cylindrical specimens $10 \mathrm{~mm}$ in diameter and $20 \mathrm{~mm}$ in length, cored perpendicularly to the hardway plane (Fig. 1), were subjected to the loading tests under dry uniaxial conditions at room temperature. The cyclic loading test was with a specified maximum stress of 140MPa (i.e., approximately $70 \%$ of the estimated uniaxial compressive strength in the preliminary test) and the minimum one of $0.5 \mathrm{MPa}$. The applied load was controlled to change linearly (lumped loading), and the loading-unloading cycle time was decided as $10 \mathrm{~s}(0.1 \mathrm{~Hz})$. In this loading rate, the strains were basically recovered in the vicinity of the minimum stress point. The completion of the loading cycle was determined by the comprehensive estimation on the behavior of specimens monitored during the test; the number of test cycles therefore was not decided in advance. The detail is mentioned in the next section.

An adjunctive comparison test with monotonic compression was performed in order to examine the difference between the cyclic and monotonic loading. The loading rate of the monotonic compression was set at $30 \mathrm{MPa} / \mathrm{s}$ referring to the cyclic test.

To monitor the behavior of the specimens during the test, axial and lateral strains, and the applied load were simultaneously measured at $0.1 \mathrm{~s}$ intervals, that is, 100 measurements were taken for one loading cycle. Two strains were detected by strain gauges with an effective length of $2.0 \mathrm{~mm}$ directly attached to the side surfaces of each 
specimen (Fig. 1). The applied load was measured by a load-cell attached within a testing machine.

\subsection{Determining the stage in the fatigue process}

In general, during the cyclic loading test, the upper peak of lateral strain roughly behaved as shown in Fig. 2 (e.g., Haimson and Kim, 1972), and the fatigue process was divided into three stages following the strain behavior. The three stages are a primary stage in which the upper peak strain increases at a decelerating rate (stage I), a second stage with linearly slight increasing rate of strain following stage I (stage II), and the third and final stage in which the upper peak strain increases at an accelerating rate and culminates in specimen failure (stage III). A similar tendency for the strain behavior of granite during cyclic loading was reported, and the behavior observed in this study was similar to that in these studies (e.g., Haimson, 1978; Kodama et al., 1992). Consequently, the stage in the fatigue process was decided by the strain behavior, and microcrack development patterns at each stage were observed to examine the granite fatigue process.

In order to prepare specimens corresponding to each stage of the fatigue process, the behavior of the strain was constantly monitored during the cyclic loading test, and the test was stopped based on the comprehensive estimation on the strain behavior of specimens. The judgment of the fatigue process stage did not depend on the number of loading cycles. The specimens classified as stage II were subdivided into early and latter stages according to the strain behavior for further examination. The behavior of the upper lateral strain during the cyclic loading tests and the stages judged by the strain behavior are summarized in Fig. 3. Meanwhile, to examine monotonic compression, two prefailure specimens stressed to 195 and 200MPa were prepared. As a result, a total of ten specimens including the intact (no-loaded) specimen were examined in this study (Table 1). 


\subsection{Microcrack detection method}

The fluorescent method proposed by Nishiyama and Kusuda (1994) was applied to identify microcracks within the specimens. The advantage of this method is to provide quick and accurate identification of microcracks with an optical microscope, and applications for examining the rock weathering process (Nishiyama and Kusuda, 1996) and rock fracturing (Nishiyama et al., 2002) were reported. Microcracks are detected based on a marked difference in brightness under ultraviolet light irradiation because they are fully filled with acrylic resin mixed with a fluorescent substance in advance. The detection limit of this approach is reportedly less than a few micrometers (Nishiyama and Kusuda, 1994). This method is efficient for detecting microcracks within granite (Chen et al., 2001). When observing thin sections of granite using the fluorescent method, the brightest parts corresponded to cracks or pores, quartz and feldspar grains were shown in blue, and other colored minerals including biotite and muscovite grains in black, under UV light (Fig. 4).

Thin sections including the axis of the specimen were prepared for detailed observation (Fig. 1). To cancel the influence of the bias due to rock anisotropy on observation, whole sections were prepared for the same orientation, parallel to the grain plane.

\section{Observation}

To examine the fatigue process of granite, crack patterns in specimens for each stage were observed. A series of crack development patterns within the specimens is shown in Fig. 5. The progress of degradation with proceeding fatigue stage was clearly observed. Significantly, many cracks developed in later stage II specimens (Fig. 5d), compared with the less stressed specimens (Figs. 5a, 5b and 5c). Most of these developed cracks were observed in feldspar grains (Fig. 5d). Cracks further increased 
and elongated in the stage III specimens (Fig. 5e). In this stage, cracks running parallel to the loading direction were dominant. Some of these long cracks cut through more than two grains. As a further examination, the characteristics of microcracks in each stage were observed in more detail.

\subsection{Crack growth during the initial degradation stage}

To examine the fatigue process at the initial degradation stage, microcracks in the intact, stage I, and early stage II specimens were compared (Fig. 6). In the stage I specimens, it was confirmed that the number of grain boundary cracks and intragranular cracks increased compared with the intact specimen (Fig. 6 a-d). Intragranular cracks were observed mainly in quartz and most of those cracks extended from the interfaces between different minerals. In some feldspar grains, many fine cleavage cracks were observed even in the intact specimen, and the growth of these cleavage cracks was identified in the stage I specimens. No marked change between specimens in stage I and early stage II was observed (Fig. 6 c-f).

\subsection{Crack growth during the second stage}

Microcrack patterns between the early and later stage II specimens were compared (Fig. 7). The most characteristic feature was that many microcracks were observed in feldspar grains in the latter stage II specimens (Fig. 7 c and d). Especially, crack arrays were concentrated in the feldspar grains located in the central part of the cluster of feldspar grains. Many of these cracks tended to arrange themselves densely and parallel to the loading direction. However, in quartz grains, no marked difference in microcrack patterns was observed between the two specimens.

\subsection{Crack growth during the final accelerated stage}

To examine the shift in the fatigue process from stage II to stage III and the breaking mechanism in stage III, microcrack development patterns in the latter stage II 
specimens and the stage III specimens were compared. As a result, long cracks which could not be identified in the stage II specimens were observed in the stage III specimens (Fig. 8). Most of these cracks had three characteristic features; that is, they ran parallel to the loading direction, their paths were beyond one grain, and cut across several grain boundaries. Some of them elongated to more than $2 \mathrm{~mm}$ and cut through several grains. Their main paths were transgranular of feldspar, and they sometimes followed the grain boundary around quartz grains instead of cutting through them (Fig. 8). Hereinafter, these long cracks with the characteristics that their paths are beyond one grain are called as intergranular cracks, but their paths sometimes followed by transgranular (or intragranular)-grain boundary system, instead of transgranular-transgranular system.

\section{Analysis}

To clarify the fatigue process in more detail, the features of crack development were analyzed by applying image analysis techniques.

\subsection{Image analysis method}

A quarter area of each thin section was selected as the reference area taking account of the symmetry. Digitalized image files of the reference area, approximately 5 X $10 \mathrm{~mm}$, were captured with a CCD camera attached to an optical microscope, applying the fluorescent approach. Cracks in each section were manually extracted and the crack images were saved at a resolution of 300 pixels $/ \mathrm{mm}$. Cleavage cracks in feldspar were excluded from the analysis in this study. Extracted cracks were classified into two types, grain boundary cracks and cracks in grains. Further, cracks in grains were subdivided into cracks in quartz and in feldspar (Fig. 9). To analyze crack growth patterns, the length and direction of each extracted crack were measured and a 
parameter 'crack population' which was determined by the sum of the crack length divided by the full dimensions of the reference area was calculated.

\subsection{Analytical results}

First, the change in the crack numbers as the fatigue process progressed was examined (Fig. 10). It was found that the crack number gradually increased as cyclic loading proceeded. For a more detailed examination, the change was analyzed by dividing cracks into cracks in feldspar and quartz (Fig. 10). The analysis indicated that there was a clear difference in growth patterns between the two cracks. That is, cracks in quartz increased suddenly in stage I and then stayed constant during stage II, and finally increased markedly before failure. Meanwhile, cracks in feldspar increased almost proportionally until stage III.

Next, the crack orientation was examined. Then, the orientation of extracted cracks was summarized at every $20^{\circ}$ (Fig.11). A clear difference between cracks in feldspar and quartz was identified. The most significant feature was that the preferential orientation parallel to the loading direction was observed in feldspar at the final stage (Fig. 11e). An increase in cracks oriented parallel or subparallel to the loading direction was also identified in the latter half of stage II specimens (Fig. 11d). Compared to the intact or first-stage specimens, it was clear that most of the newly generated and elongated cracks in feldspar oriented parallel to the loading direction. On the other hand, no clear preferred orientation of cracks was observed in quartz grains throughout the test.

To examine crack generation, the behavior of relatively short cracks observed in the grains was analyzed. This was because the short cracks were thought to be closely related to the newly generated cracks. Fig. 12 shows a frequency distribution chart of crack length, and, to compare two cracks in feldspar and quartz, the unit (i.e., number) of their vertical axes was adjusted by the area of each mineral. In both minerals, a slight increase in short cracks in the range of $0.1 \mathrm{~mm}$ was identified from the un-loaded stage 
to stage I. A characteristic difference between the two cracks was observed in the latter half of stage II. That is, in feldspar short cracks sharply increased at this stage, but no clear increase was identified in quartz grains. Significant growth of cracks of less than $0.1 \mathrm{~mm}$ length, however, was observed in stage III.

\section{Discussion}

Considering the observational and analytical results, the granite degradation mechanism due to fatigue process is discussed.

One feature of the early fatigue process is that the strain growth rate gradually decreases and finally transits to the temporary linearly increasing stage. To clarify this phase, the intact, stage I, and first half of stage II specimens were compared. The analytical results showed that the crack population in quartz grains increased during stage I, but there was little further development until stage II (Fig. 10). On the other hand, only a slight increase in the crack population was observed in feldspar grains throughout these stages (Fig. 10). In the stage I and II specimens, many microcracks in quartz grains stayed within one grain and did not elongate to the neighboring grains (Fig. 6), although the average crack length increased with the fatigue process. A comparative observation of grain boundary cracks in appropriate specimens showed that the opening width of the cracks widened slightly in some parts in stage I and the first phase of stage II. Therefore, at the initial degradation stage, crack growth in quartz grains is thought to be the predominant mechanism. It is estimated that many portions with potential crack development in quartz grains were damaged during the early cycles of loading, while further loading did not induce further cracking immediately following the first-stage damage. However, it is quite unlikely to think that the one cycle of loading develops cracks in all portions of cracking potentiality, and practically the prior loading makes a change on the situation within the specimens. Therefore, the new cracking is awhile 
induced at the subsequent loading. Needless to add, the portions fit to the cracking condition gradually decrease with further loading. It is assumed that this decrease in crack growth is one of the causes of the slowdown in the strain growth rate in the initial degradation stage and that the fatigue process moves on to the next stage, in which the damage increases slowly and steadily.

Next, the reason why the strain behavior was in the steady increase for a long time during stage II is discussed. The observation and analysis of the stage II specimens showed little development of cracks in quartz grains, whereas in feldspar grains the number of microcracks increased during this stage (Figs. 10 and 11). Many of these new cracks in feldspar were short (less than $0.1 \mathrm{~mm}$ in length) (Fig. 12), and their orientation showed a certain degree of bias to the orientation parallel to the loading direction (Fig. 11). It is therefore thought that the applied load-unload was mainly expended in two mechanisms; the growth or initiation of microcracks in feldspar grains and the open-close of cracks developed until this stage. The growth rate of microcracks in feldspar grains was estimated to be very slow, and they barely grew into intergranular cracks in this phase. Inevitably, it is inferred that the influence of the damage within feldspar grains on the outside of grains was small at this stage. Consequently, during the second stage, the macroscopic behavior of strain growth was stable without rapid increase.

Finally, the transition from stage II to stage III and the accelerating increase of lateral strain during the final stage were examined. In the stage III specimens, many long cracks which ran parallel to the loading direction were observed, and most of them cut through several grains and grew into intergranular cracks (Fig. 8). Most parts of these cracks ran through feldspar grains. Statistical analysis indicated the preferential orientation of cracks parallel to the loading direction in feldspar (Fig. 11). Therefore, these long intergranular cracks were probably formed by linking of the intragranular 
cracks generated during stage II in feldspars. It is thought that the formation of long intergranular cracks leads the fatigue process from the second stage into the final stage where the strain increases at an accelerating rate. This suggests that in the final stage, the further development of long cracks which cut through several grains causes the strain to increase at an accelerating rate and leads to ultimate fatigue failure. The dominant mechanism on crack development on this phase is estimated to be the crack coalescence.

In addition, the results for cyclic loading specimens were compared with those for monotonic compressive specimens stressed to near failure. Long intergranular cracks such as those found in the stage III specimens were not identified within monotonic compressive specimens. Crack patterns in quartz and feldspar grains were analyzed in the same way. As a result, the preferred orientation of cracks in feldspar grains was more conspicuous in the cyclic loading specimens (Figs. 11 and 13). In contrast, grain boundary cracks were more abundant in the monotonic compressed specimens (Fig. 14).

\section{Conclusions}

In order to examine the fatigue process of granite, intact Westerly granite specimens were subjected to a cyclic loading test under uniaxial compression at a maximum of $140 \mathrm{MPa}$ at room temperature, and crack growth patterns within them were analyzed by microscopic observation and statistical techniques. A series of specimens for analysis, of which the stage in the fatigue process was determined by the strain behavior monitored during the test, were examined. The fatigue process was divided into three characteristic stages; a primary stage in which the upper peak strain increased at a decelerating rate (stage I), a second stage with linearly slight increasing rate of strain following stage I (stage II), and the third stage in which the upper peak strain increased at an accelerating rate and culminated in specimen failure (stage III). The 
stage II was subdivided into first and second half to examine the fatigue process in more detail. Additionally, these specimens were compared with specimens stressed to near breaking strength by monotonic compression in order to validate the differences between the two.

As a result, at the initial degradation stage, distinguishing crack growth was identified in quartz grains. It is estimated that the slowdown in the strain growth rate at this stage was caused by the stepwise decrease in crack growth, that is, the portions with cracking potentiality were damaged in the early loading cycles, and no further damage occurred immediately following the first-stage damage.

In the second stage, no significant crack growth in quartz grains was identified. On the other hand, in feldspar grains, development of cracks with a preferential orientation parallel to the loading direction was observed, but they did not grow into intergranular cracks by cutting across the grain boundaries during this stage. Consequently, it was found that a gradual progress of microcracks within feldspar grains was dominant during the second stage, and this is because the strain growth rate was in a linearly slight increasing.

In the final accelerated stage, many intergranular cracks running parallel to the loading direction were identified. It is obvious that these long intergranular cracks were formed mainly by the linking and growth of the intragranular cracks in feldspars, which were generated during the former stages. Their formation leads the fatigue process from the second stage to the final stage with a sharp increase in lateral strain, and their further development seems to lead the whole specimen to ultimate fatigue failure.

A comparison with the specimens subjected to the monotonic compression indicated that the characteristic crack growth patterns after stage II were specific to the cyclic loading operation. 


\section{References}

Åkesson, U., Hansson, J., Stigh, J., 2004. Characterisation of microcracks in the Bohus granite, western Sweden, caused by uniaxial cyclic loading, Engineering Geology $72,131-142$.

Burdine, N.T., 1963. Rock failure under dynamic loading conditions, Society of Petroleum Engineers Journal, March 1963, 1-8.

Chen, Y., Wang, C.-Y., 1980. Thermally induced acoustic emission in Westerly granite, Geophysical Research Letters 7(12), 1089-1092.

Chen, Y., Nishiyama, T., Ito, T., 2001. Application of image analysis to observe microstructure in sandstone and granite, Resource Geology 51(3), 249-258.

Costin, L.S., Holcomb, D.J., 1981. Time-dependent failure of rock under cyclic loading, Tectonophysics 79, 279-296.

Eberhardt, E., Stead, D., Stimpson B., 1999. Quantifying progressive pre-peak brittle fracture damage in rock during uniaxial compression, International Journal of Rock Mechanics and Mining Science 36, 361-380.

Faulkner, D.R., Mitchell, T.M., Healy, D., Heap, M.J., 2006. Slip on 'weak' faults by the rotation of regional stress in the fracture damage zone, Nature 444, 922-925.

Friedmana, M., Perkinsb, R.D., Greenb, S.J., 1970. Observation of brittle-deformation features at the maximum stress of westerly granite and solenhofen limestone, International Journal of Rock Mechanics and Mining Science \& Geomechanics Abstracts 7(3), 297-302.

Haimson, B.C., Kim C.M., 1972. Mechanical behavior of rock under cyclic fatigue, Proceedings of thirteenth Symposium on Rock Mechanics, Illinois, USA, 845-863. Haimson, B.C., 1978. Effect of cyclic loading on rock, In Dynamic Geotechnical Testing, ASTM STP654, Philadelphia, USA, 228-245. 
Hardy, H.R.Jr., Chugh, Y.P., 1970. Failure of geologic materials under low-cycle fatigue, Proceedings of the 6th Canadian Symposium on Rock Mechanics, Montreal, Canada, 33-47.

Heap, M.J., Faulkner, D.R., 2008. Quantifying the evolution of static elastic properties as crystalline rock approaches failure, International Journal of Rock Mechanics and Mining Science 45, 564-573.

Heap, M.J., Vinciguerra, S., Meredith, P.G., 2009. The evolution of elastic moduli with increasing crack damage during cyclic stressing of a basalt from Mt. Etna volcano, Tectonophysics 471, 153-160.

Kodama, J., Ishizuka, Y., Abe, T., Ishijima, Y., 1992, Fatigue, Creep Properties and Long-term Strength of Granite under Uniaxial Compression, Journal of MMIJ 108(3), 182-186.

Lau, J.S.O., Chandler, N.A., 2004. Innovative laboratory testing, International Journal of Rock Mechanics and Mining Science 41, 1427-1445.

Martin, C.D., Chandler, N.A., 1994. The progressive fracture of Lac du Bonnet granite, International Journal of Rock Mechanics and Mining Science 31, 643-659.

Nishiyama, T., Kusuda, H., 1994. Identification of pore spaces and microcracks using fluorescent resins, International Journal of Rock Mechanics and Mining Science \& Geomechanics. Abstracts 31, 369-375.

Nishiyama, T., Kusuda, H., 1996. Application of a fluorescent technique to the study of the weathering process, Engineering Geology 43, 247-253.

Nishiyama, T., Chen, Y., Kusuda, H., Ito, T., Kaneko, K., Kita, H., Sato, T., 2002. The examination of fracturing process subjected to triaxial compression test in Inada granite, Engineering Geology 66, 257-269.

Scholz, C.H., 1968. Microfracturing and the Inelastic Deformation of Rock in Compression, Journal of Geophysical Research 73(4), 1417-1432. 
Scholz, C.H., Koczynski, T.A., 1979. Dilatancy anisotropy and the response of rock to large cyclic loads, Journal of Geophysical Research. B 84(110), 5525-5534.

Suresh, S., 1998. Fatigue of materials, Cambridge UP, 1-34.

Suzuki, K., Nishimatsu, Y., Heroesewojo, R., 1970. The statistical distribution of fatigue life and S-N curve of rocks, Journal of MMIJ 86, 353-358.

Tapponnier, P., Brace, W.F., 1976. Development of Stress-Induced Microcracks in Westerly Granite, International Journal of Rock Mechanics and Mining Science \& Geomechanics Abstracts. 13, 103-112.

List of table and figures

Table 1. Summary of the tested specimens.

Fig. 1. Schematic figure showing the size and orientation of each specimen. To prevent the effects of rock anisotropy, whole thin sections were prepared for the same direction.

Fig. 2. Common S-N curve of the fatigue process in universal materials. The process was classified into three stages following the strain behavior.

Fig. 3. Behavior of maximum lateral strain in the tested specimens. To prepare specimens corresponding to each stage, the test was stopped depending on the strain behavior of the specimen.

Fig. 4. Typical microscopic appearance of tested specimens (intact specimen). (a) observation by a fluorescent method (under UV light); light (white) parts correspond to cracks and/or pores, (b) plane polarized light, (c) crossed nicols.

Fig. 5. Microcrack growth patterns with proceeding fatigue stage. The loading direction was vertical. (a) Intact specimen, (b) Specimen in the initial degradation stage: specimen I-1, (c) Specimen in early stage II: specimen II-1, (d) Specimen in later 
stage II: specimen II-2, and (e) Specimen during the final accelerated stage: specimen III-3.

Fig. 6. Microcrack development pattern during the initial degradation stage. (a, b) Intact specimen, (c, d) Specimen in the stage I, and (e, f) Specimen in early stage II. (a, c, e) Fluorescent images, (b, d, f) polarized images with extracted crack/pore parts from the fluorescent images (orange/red). Yellow arrows indicate the growth of cleavage cracks in feldspar. The loading direction was vertical. Fd: feldspar, Qz: quartz, Bi: biotite.

Fig. 7. Crack growth during the steady and long state stage (stage II). (a, b) Specimen in early stage II, (c, d) Specimen in later stage II: Microcrack arrays were observed in the center of the feldspar cluster in the later stage II specimen. $(a, c)$ Fluorescent images, (b, d) polarized images with extracted crack/pore parts from the fluorescent images (orange/red). The loading direction was vertical. Fd: feldspar.

Fig. 8. Intergranular cracks running parallel to the loading direction observed in the final accelerated stage (stage III). Arrows represent the crack path following the intragranular in feldspar (thick arrow) and grain boundary around quartz grain (thin arrow). (a) Fluorescent image, (b) polarized image with extracted crack/pore parts from the fluorescent images (orange/red). The loading direction was vertical. Fd: feldspar, Qz: quartz, Bi: biotite.

Fig. 9. Manual classification of extracted cracks. (a) Fluorescent image, (b) polarized image, (c) extracted crack image: grain boundaries (yellow lines), cracks in quartz grains (green lines), and in feldspar grains (red lines). A part of the reference area.

Fig. 10. Crack population at each stage of the fatigue process.

Fig. 11. Orientation of cracks in quartz and feldspar grains. The loading direction was vertical. (a) Intact specimen, (b) Specimen in the initial degradation stage: specimen I-1, (c) Specimen in early stage II: specimen II-1, (d) Specimen in later 
stage II: specimen II-2, and (e) Specimen during the final accelerated stage: specimen III-3.

Fig. 12. Frequency distribution charts of the length of each extracted crack in feldspar (a) and in quartz (b) of tested specimens.

Fig. 13. Orientation of cracks in quartz and feldspar grains (specimens stressed by monotonic compression). The loading direction was vertical. (a) 195MPa specimen, (b) 200MPa specimen.

Fig. 14. Comparison in grain boundary crack development between cyclic loading and monotonic loading. 
Table 1

Summary of the tested specimens.

\begin{tabular}{ccccc}
\hline Sample number & Maximum stress (MPa) & Loading cycle & \multicolumn{2}{c}{ Maximum strains at the final cycle (microstrains) } \\
\cline { 4 - 5 } & & & lateral & - \\
\hline \hline intact & - & 100 & - & $-2,589$ \\
I-1 & 140 & 1,488 & 899 & $-3,037$ \\
I-2 & 140 & 7,000 & 740 & $-2,540$ \\
II-1 & 140 & 35,728 & 1,634 & $-2,970$ \\
II-2 & 140 & 15,000 & 2,085 & $-3,556$ \\
III-1 & 140 & 26,470 & 4,573 & $-2,650$ \\
III-2 & 140 & 42,640 & 2,268 & $-3,215$ \\
III-3 & 140 & - & 2,956 & $-4,076$ \\
\hline M-195 & 195 & - & 2,108 & $-3,170$ \\
M-200 & 200 & & 1,835 & \\
\hline
\end{tabular}


Fig. 1

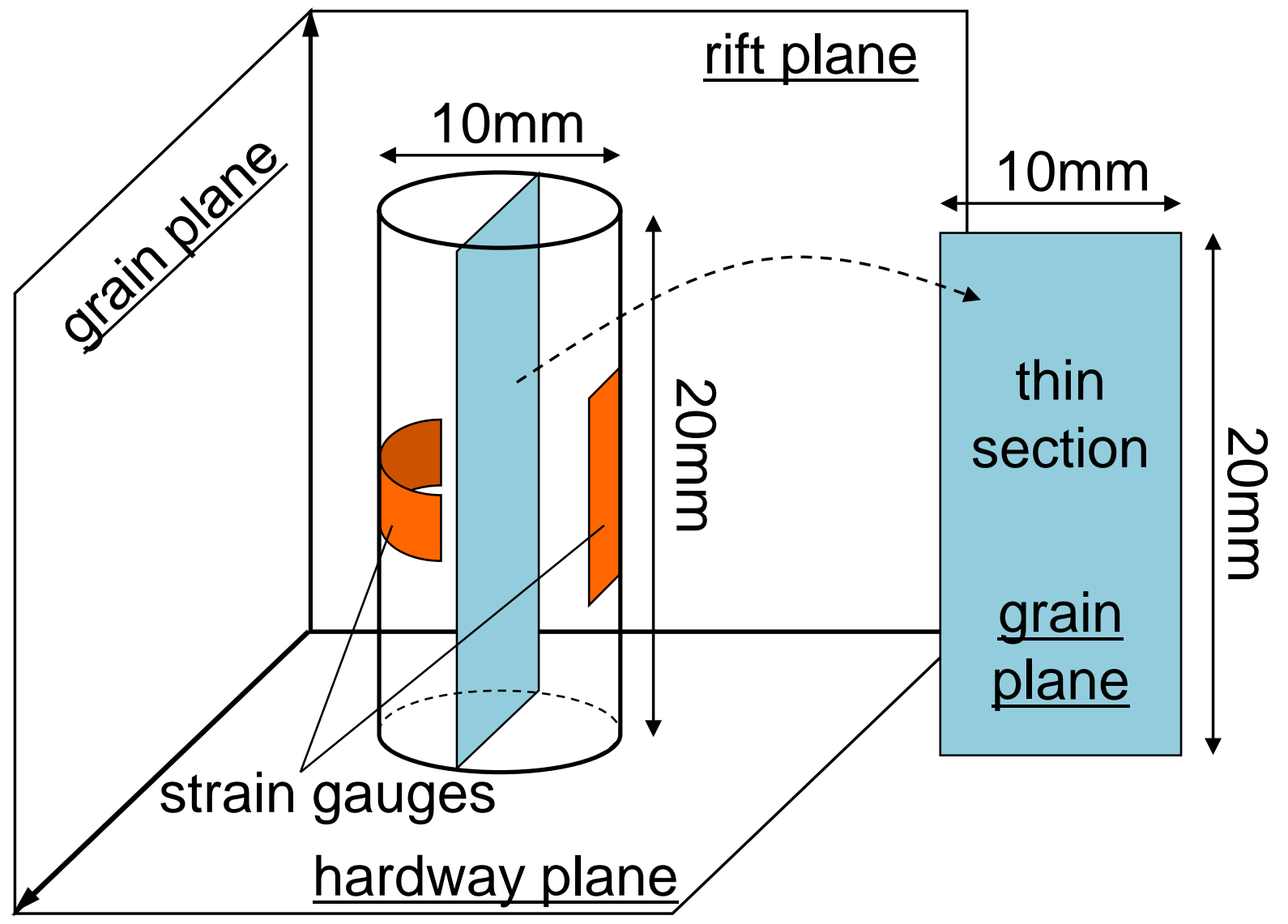


Fig. 2

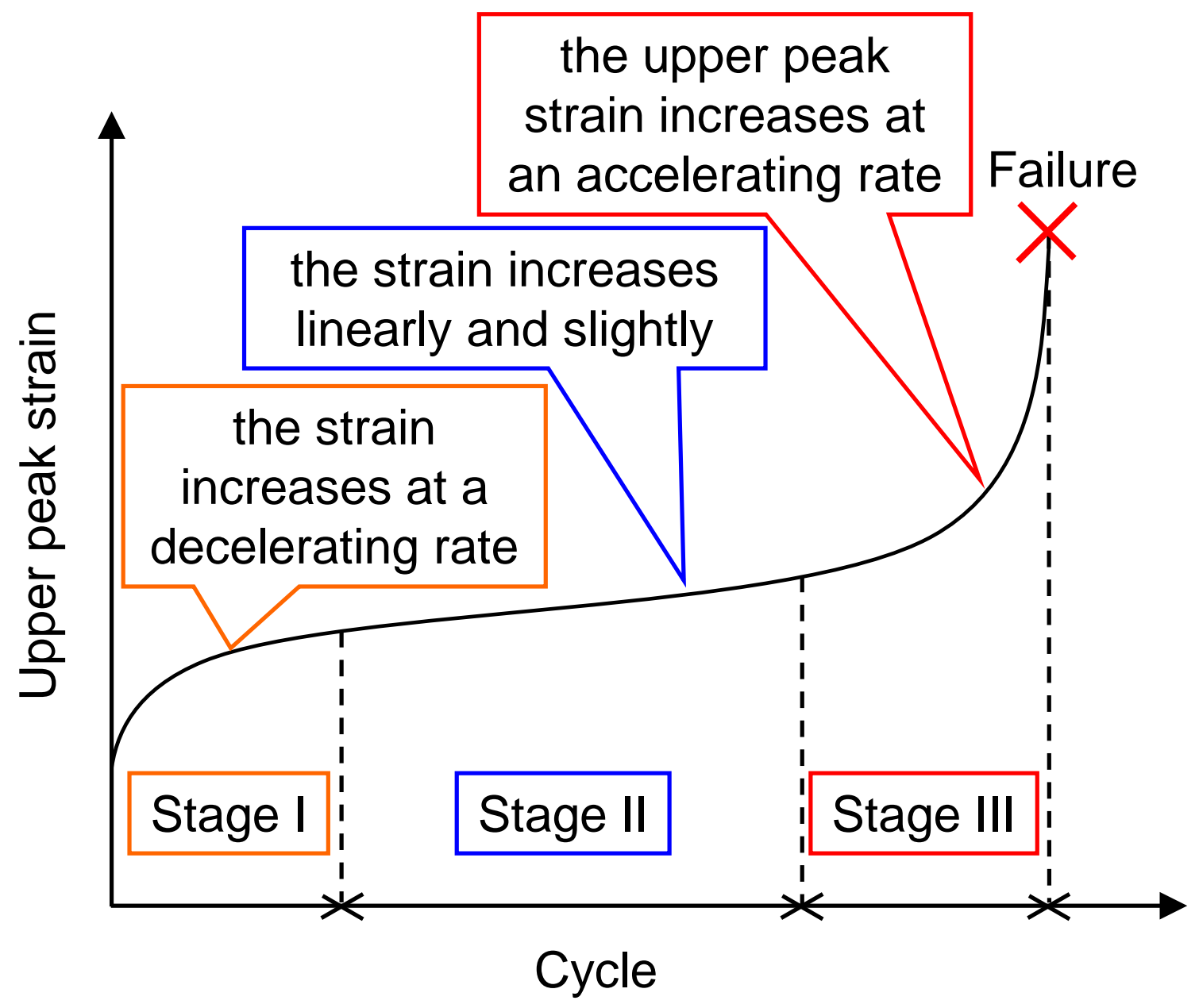


Fig. 3

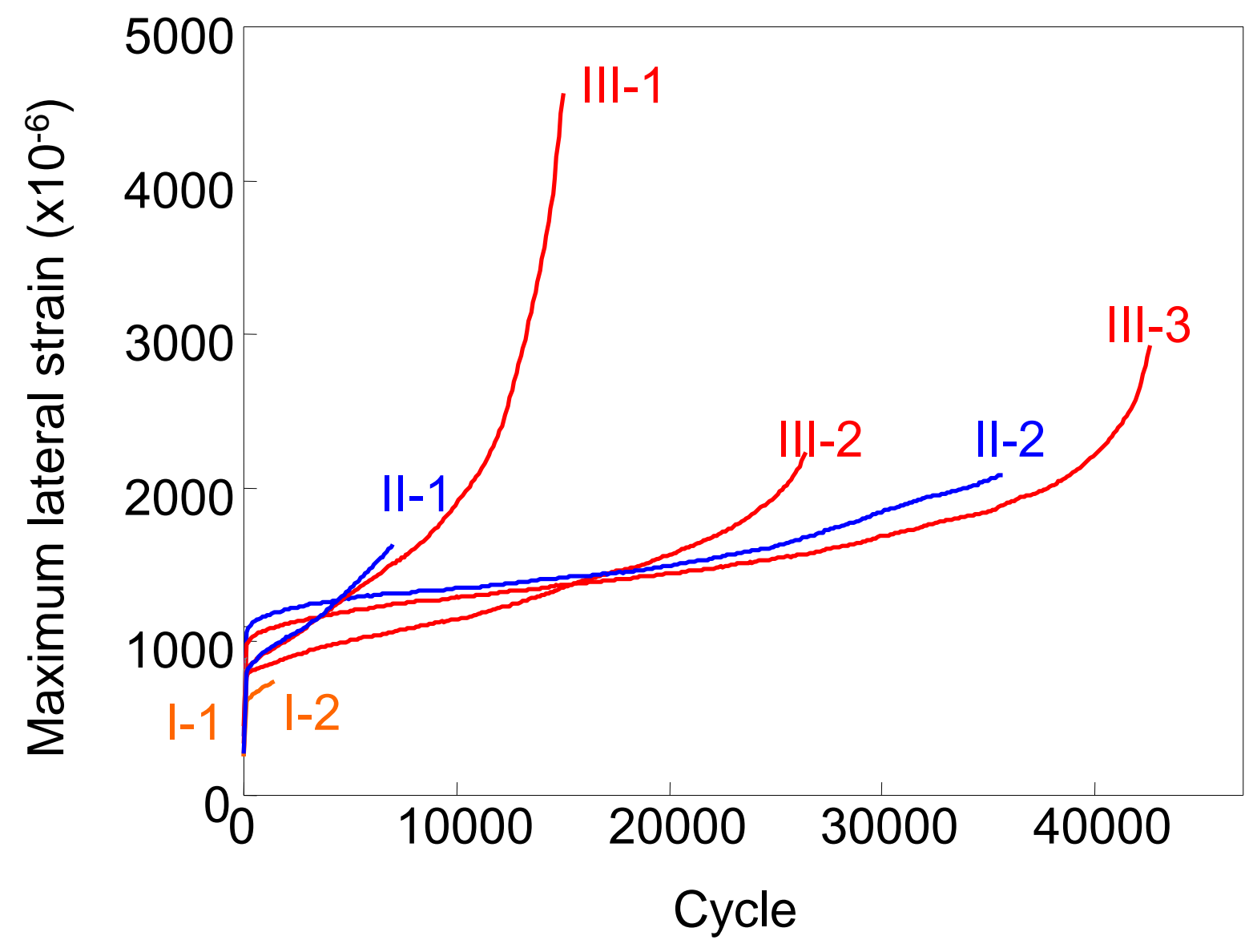


Fig. 4
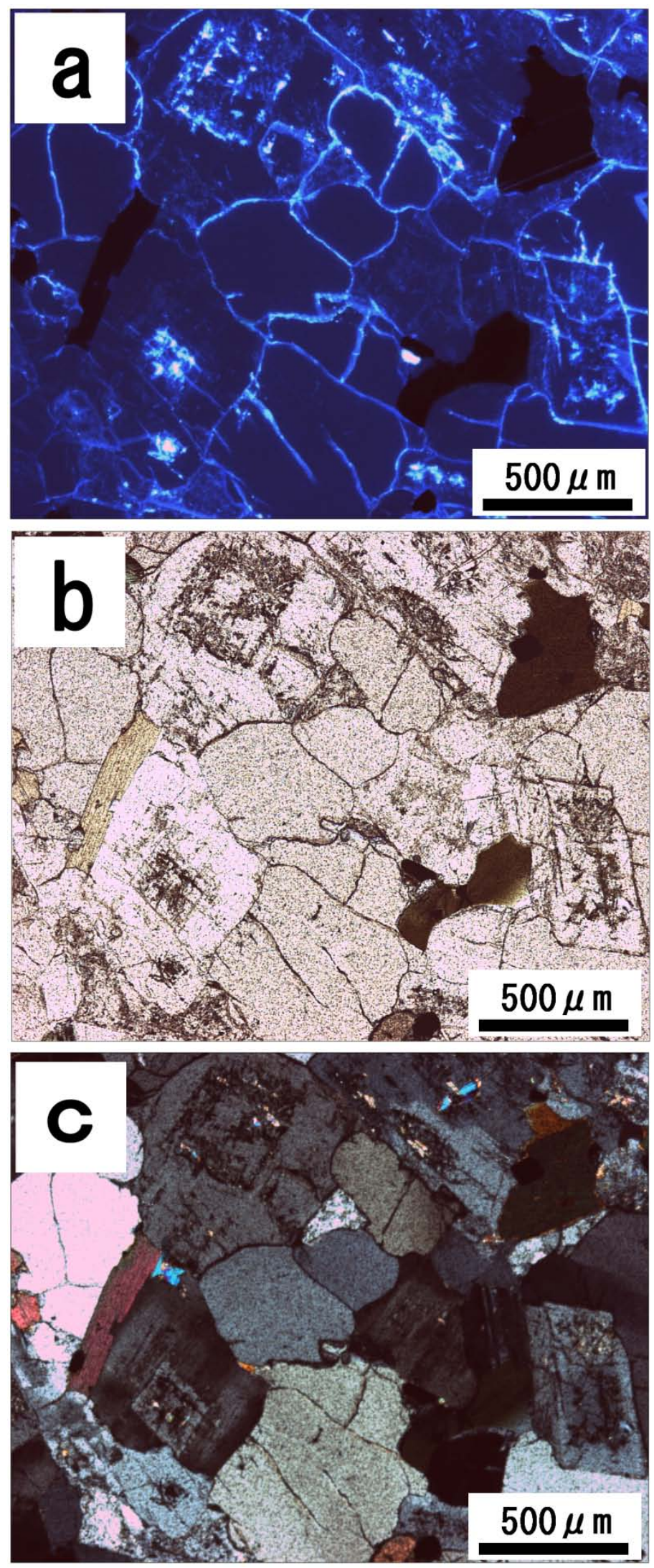
Fig. 5
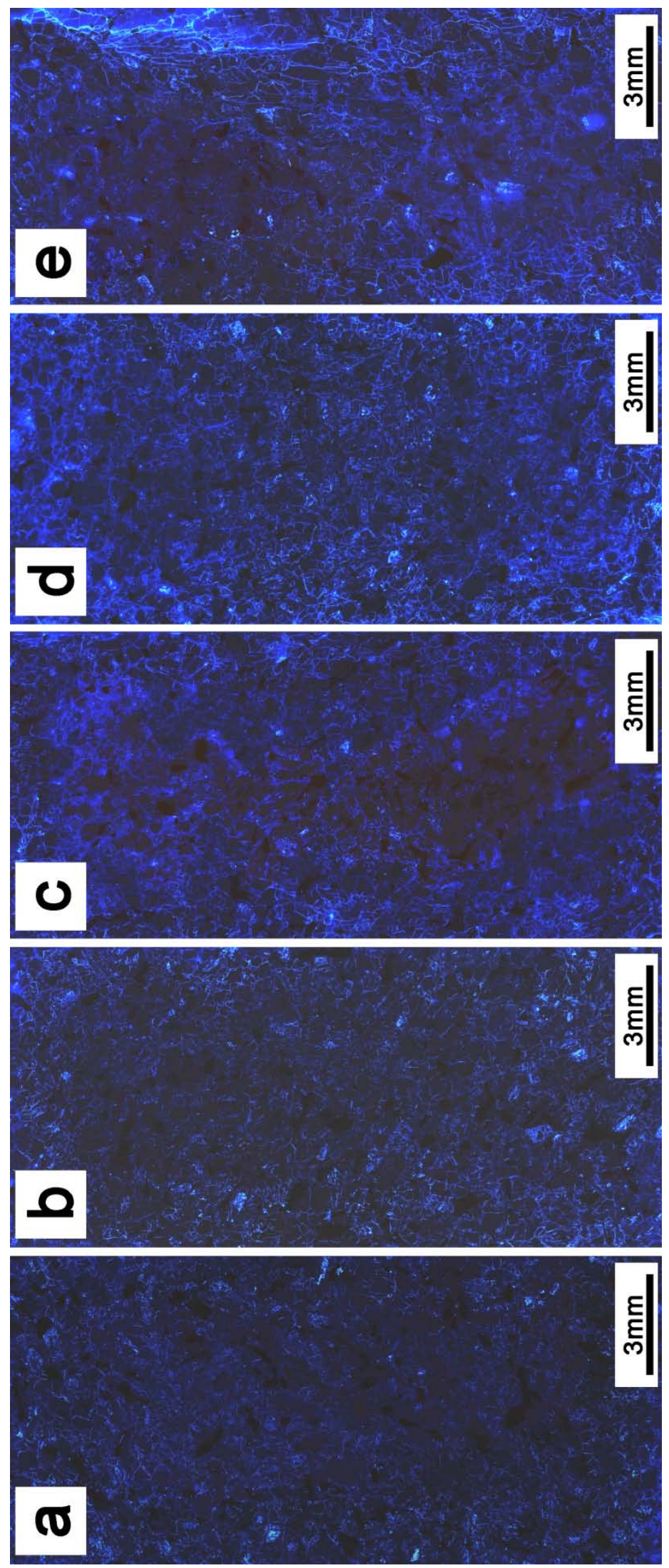
Fig. 6
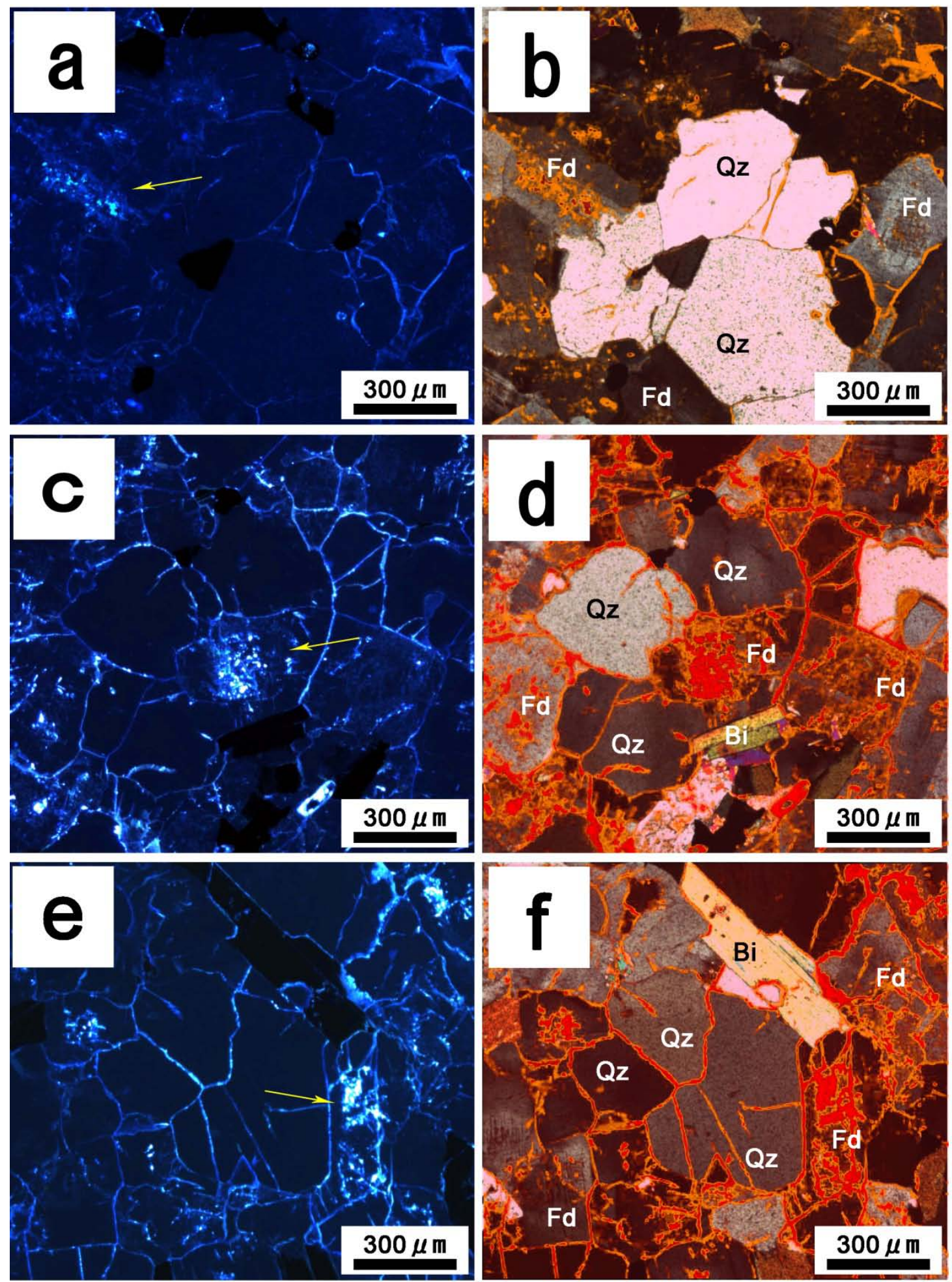
Fig. 7
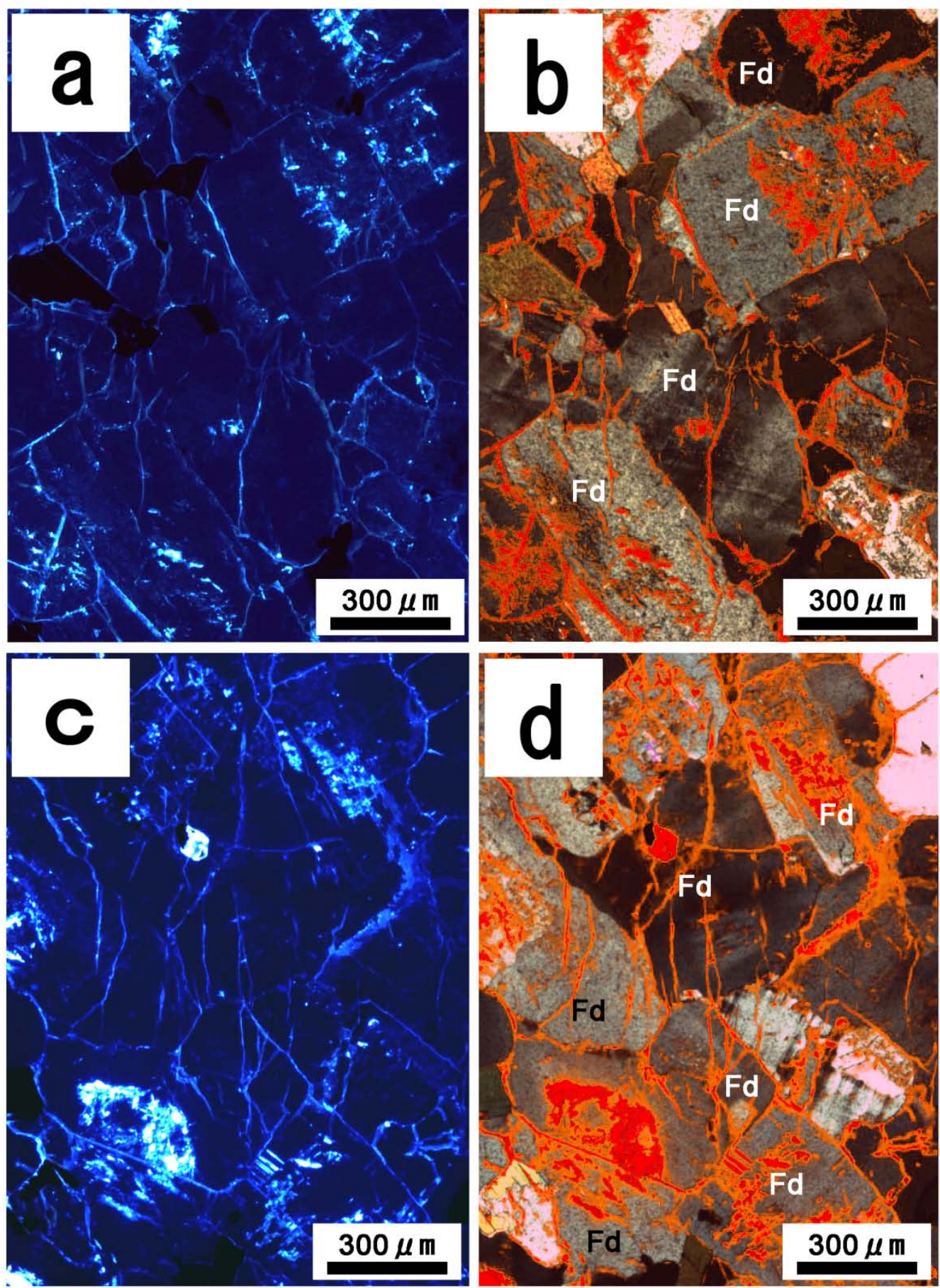
Fig. 8
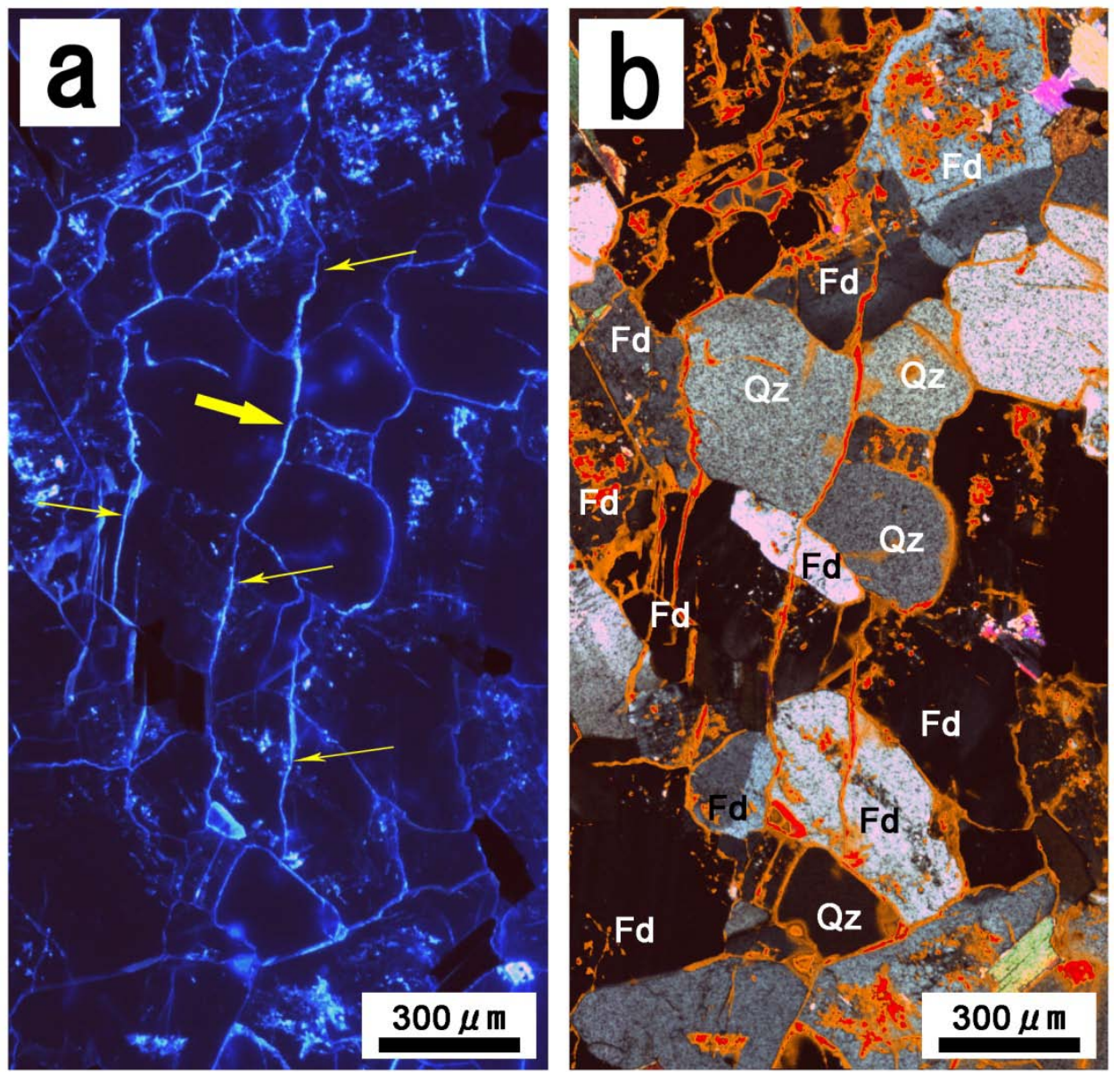
Fig. 9
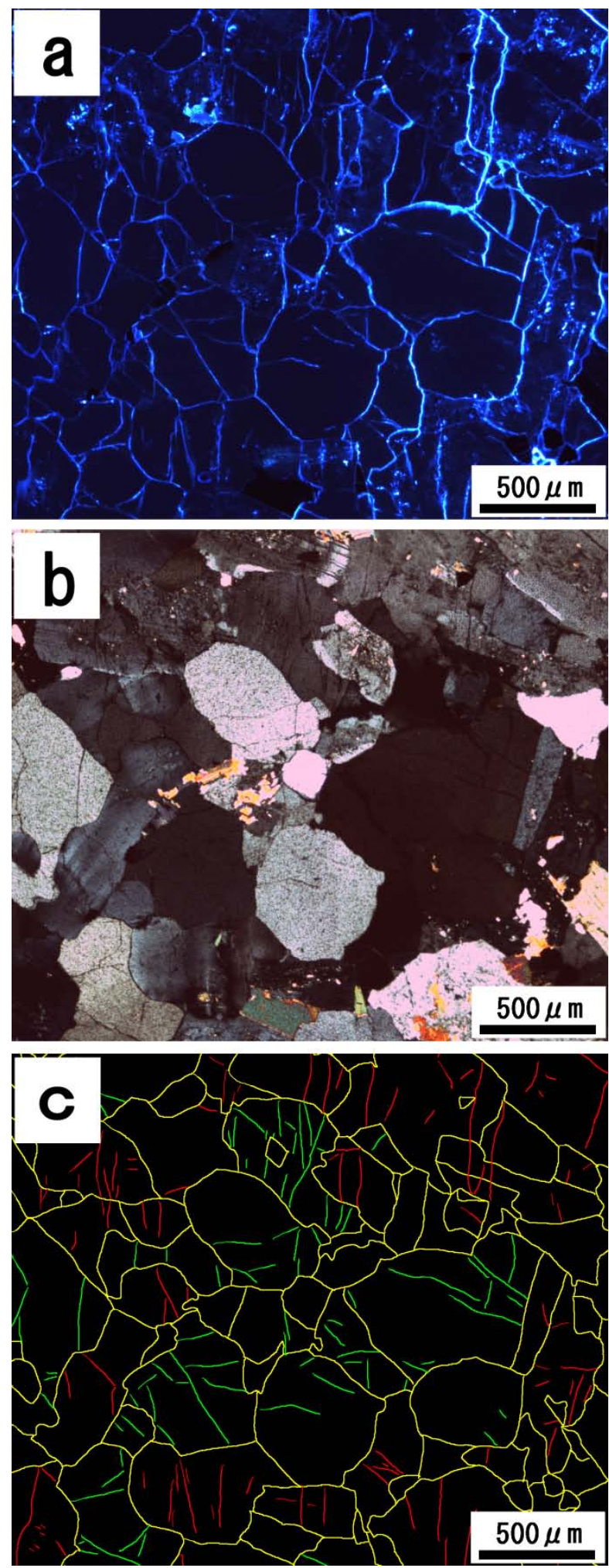
Fig. 10

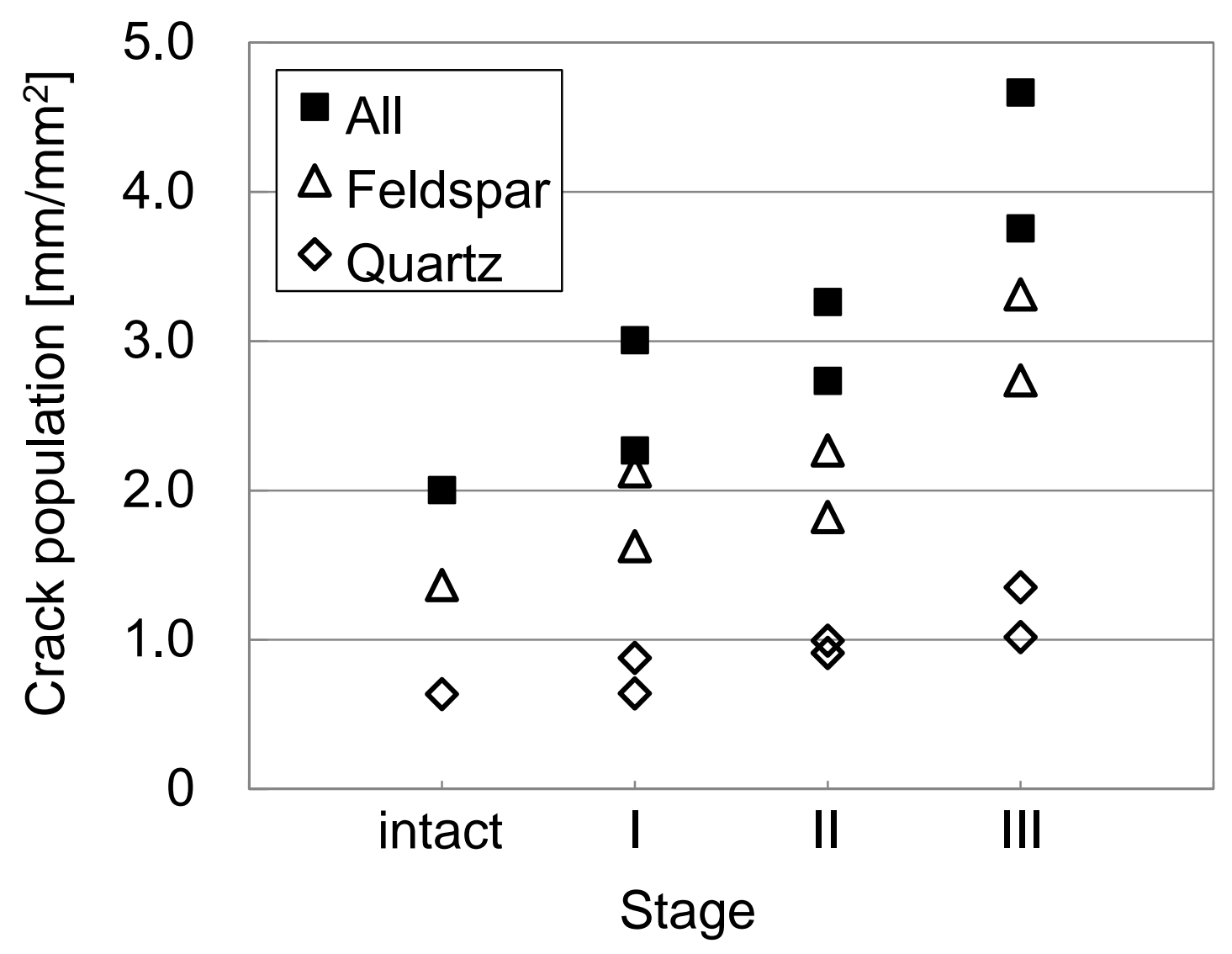


Fig.11

Feldspar

a

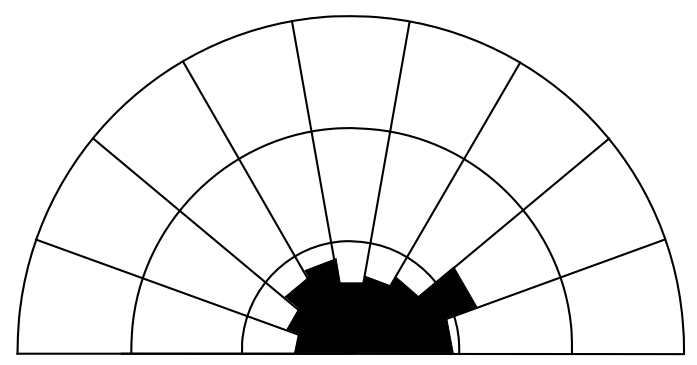

b

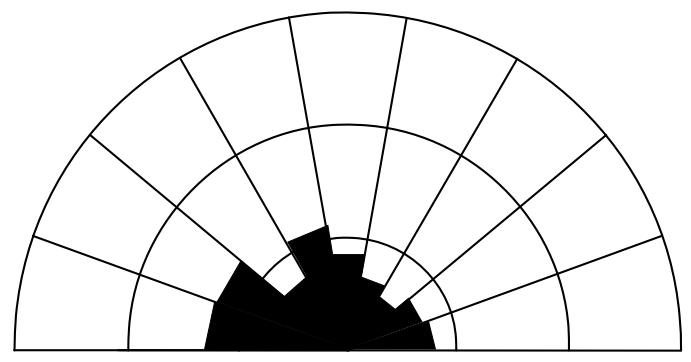

c

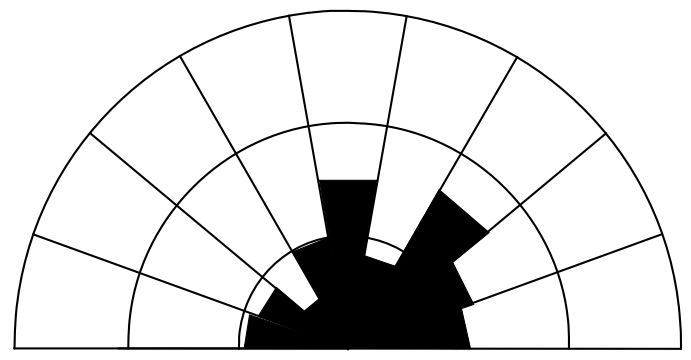

d
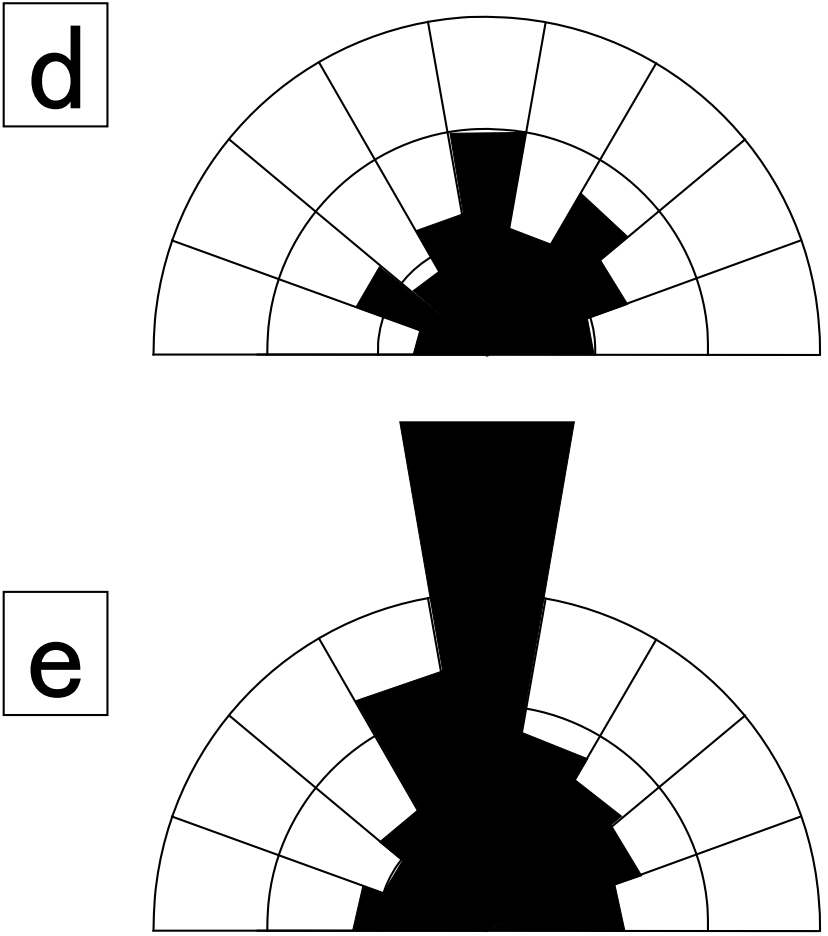

$\begin{array}{llll}0.6 & 0.4 & 0.2 & 0\end{array}$

Crack population $\left[\mathrm{mm} / \mathrm{mm}^{2}\right]$

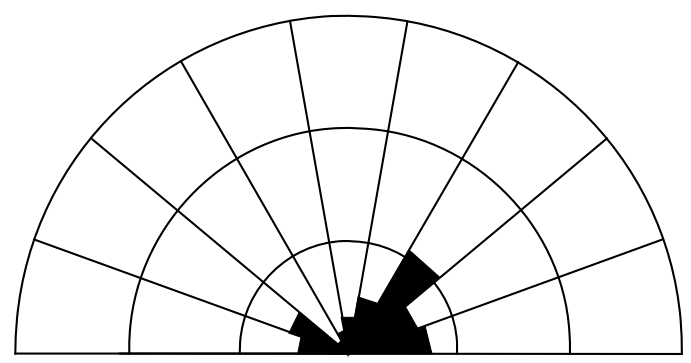

Quartz
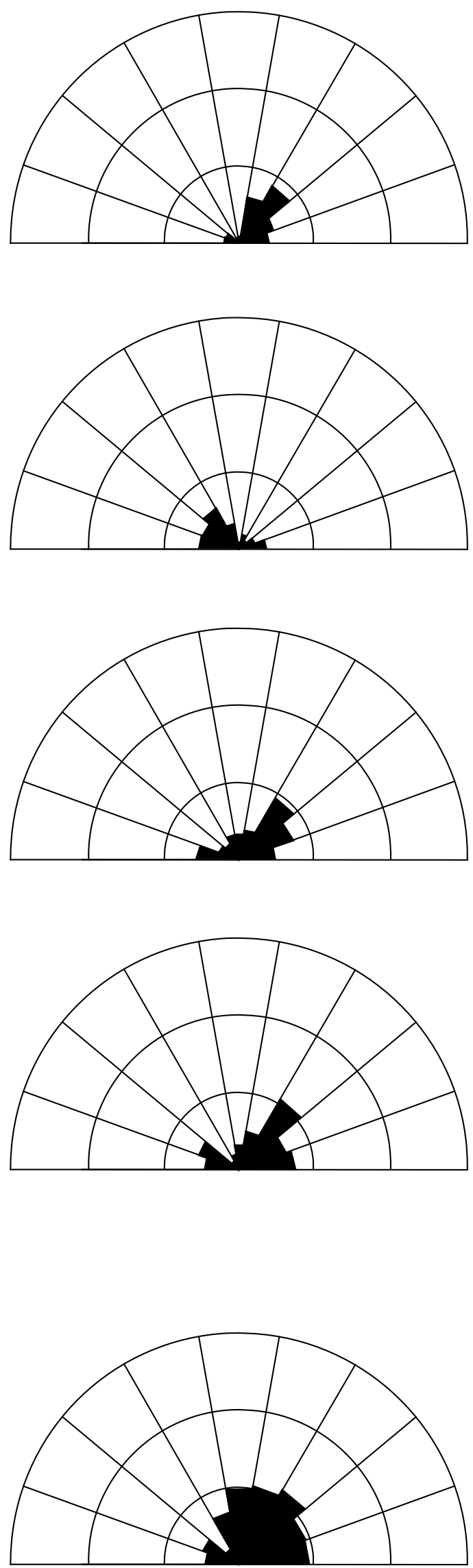

$\begin{array}{llll}0.6 & 0.4 & 0.2 & 0\end{array}$

Crack population $\left[\mathrm{mm} / \mathrm{mm}^{2}\right]$ 
Fig. 12
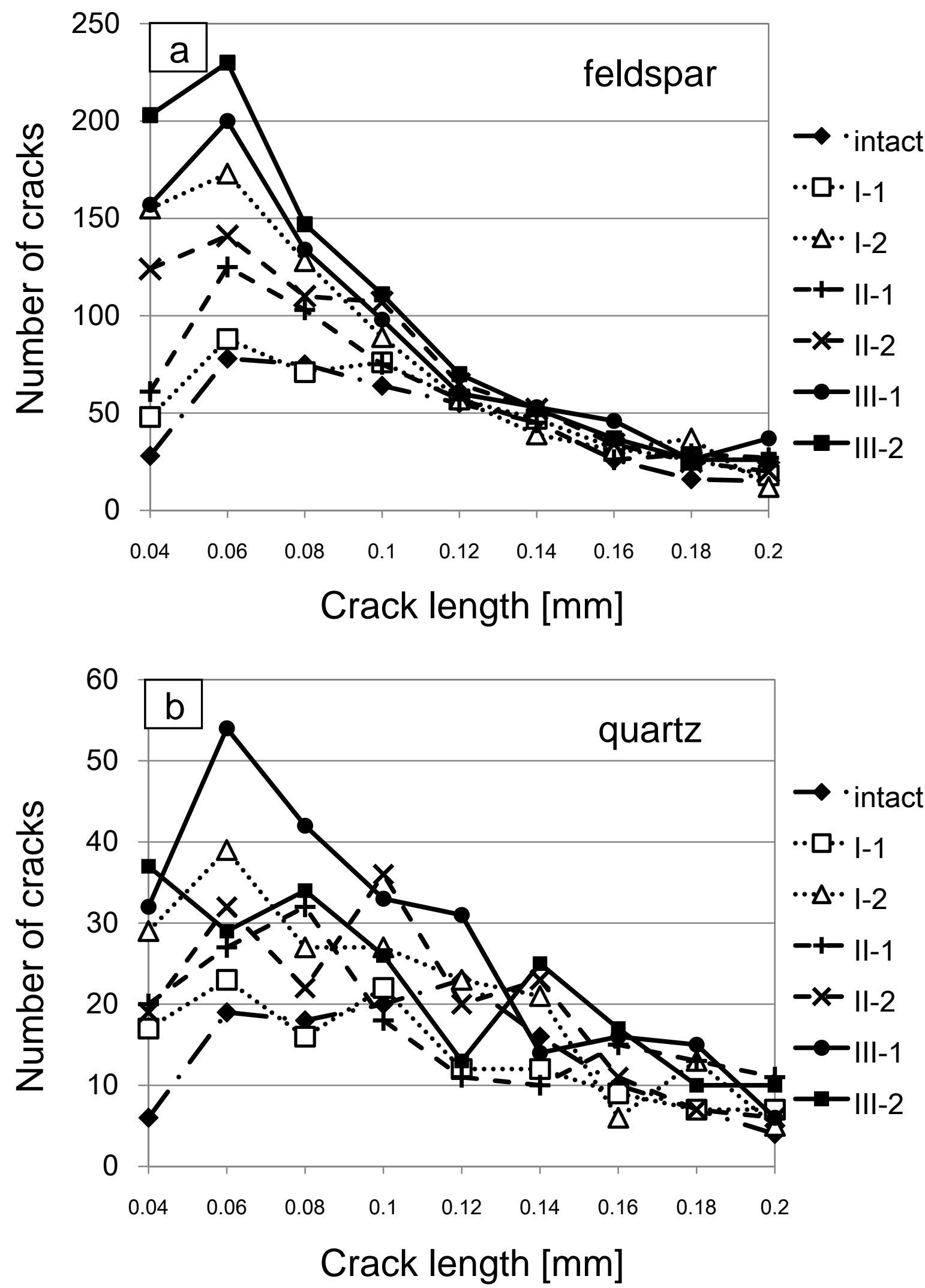
Fig.13

Feldspar

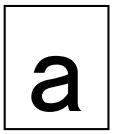

b
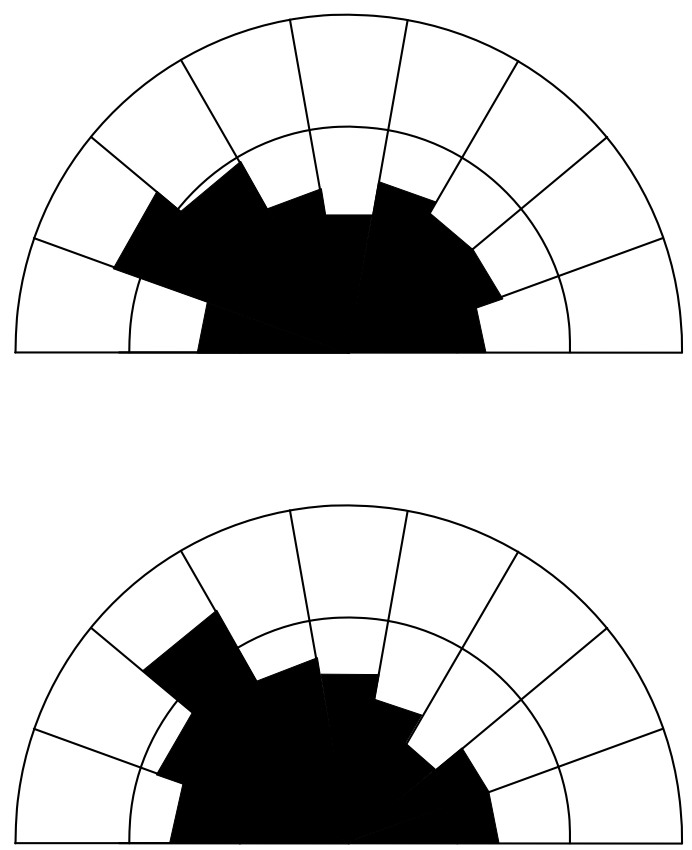

$\begin{array}{llll}0.6 & 0.4 & 0.2 & 0\end{array}$

Crack population $\left[\mathrm{mm} / \mathrm{mm}^{2}\right]$
Quartz
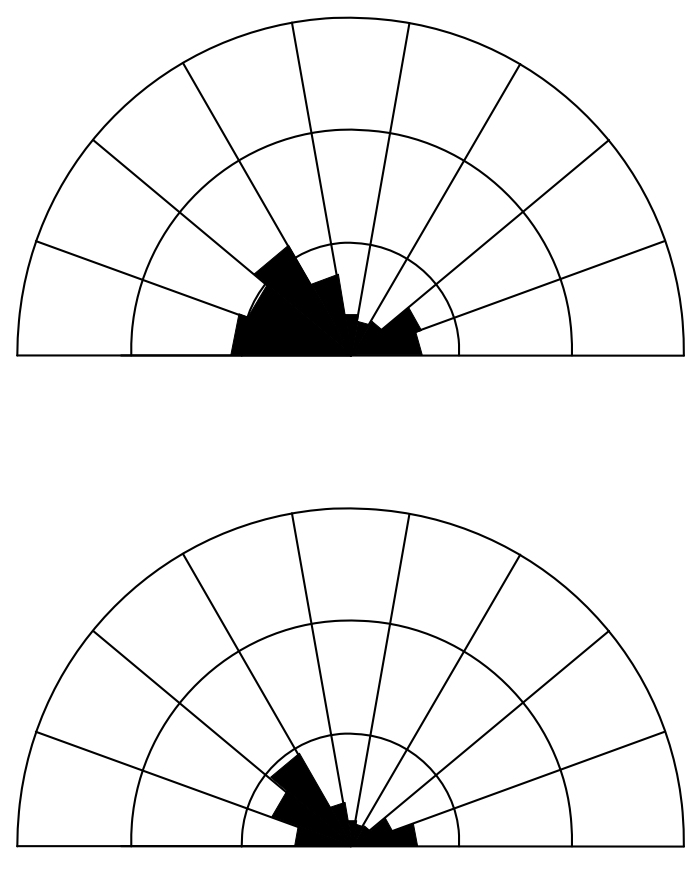

$\begin{array}{llll}0.6 & 0.4 & 0.2 & 0\end{array}$

Crack population $\left[\mathrm{mm} / \mathrm{mm}^{2}\right]$ 
Fig. 14

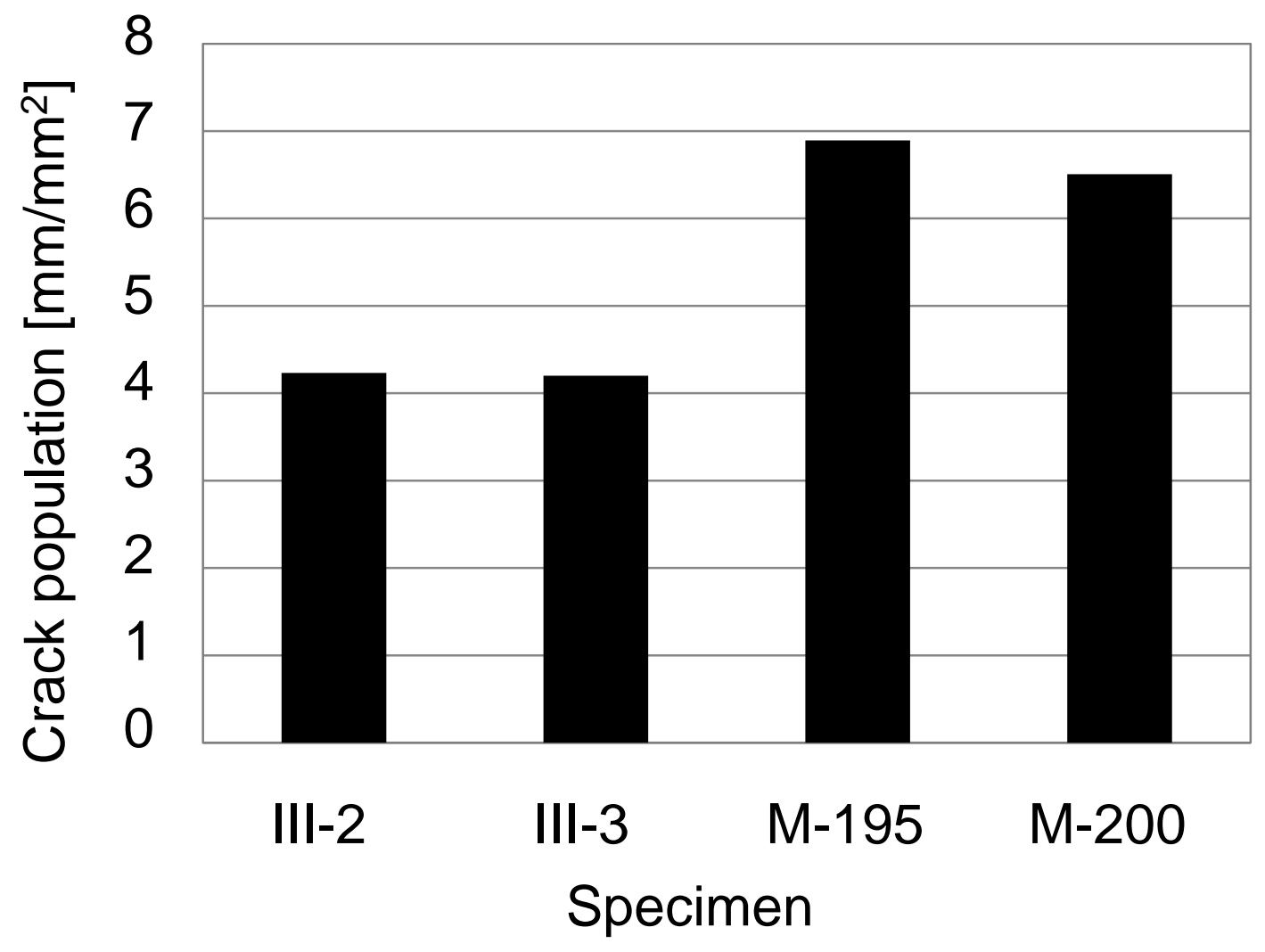

